\title{
“¿Nacionales o Republicanos? —itú decides la historia! —” el mito de 'las dos Españas' en los videojuegos Sombras de Guerra (2007/2008) y 1936, España en llamas (2012) ${ }^{1}$
}

\author{
Daniela Kuschel \\ Universidad de Mannheim
}

\begin{abstract}
Resumen:
Los dos videojuegos Sombras de Guerra y España en llamas, que representan hechos históricos de la Guerra Civil española, pertenecen a dos géneros diferentes —el primero es un juego de estrategia en tiempo real y el segundo un videojuego de disparos (o shooter) en primera persona. Tratan el contexto histórico según las convenciones de los géneros y disponen de escenarios contrafácticos en las que los republicanos pueden ganar la Guerra Civil si el jugador tiene la destreza necesaria. Lo que llama la atención es que se perpetúa el mito de las dos Españas, lo que parece ser parte integral de la mecánica y del sistema de los juegos. No obstante, hay jugadores que se niegan a cumplir las reglas y condiciones del juego, lo que les permite cuestionar las viejas tesis y la perpetuación del mito.
\end{abstract}

Palabras clave: videojuegos, memoria histórica, Guerra Civil española, mito de 'las dos Españas'

\begin{abstract}
:
The two video games Sombras de Guerra and España en llamas, that represent historical events of the Spanish Civil War, belong to two different genres - the first is a real-time strategy game and the second a first-person shooter. Both deal with the historical context according to the conventions of the genres and they include counterfactual scenarios in which the 'Republicans' can win the Civil War, if the player has the necessary skills. It's interesting that the myth of 'the two Spains' is perpetuated and that this fact seems to be an integral part of the mechanics and the games' system. However, there are players who refuse to comply with the rules and conditions of the game, which allows them to question old theses and the perpetuation of the myth.
\end{abstract}

Keywords: video games, memory culture, Spanish Civil War, myth of 'the two Spains'

\footnotetext{
${ }^{1}$ Este artículo retoma en parte los resultados del análisis de los dos videojuegos incluidos en mi tesis doctoral que se publicó en 2019 (Spanischer Bürgerkrieg goes Pop, Bielefeld: transcript). No obstante, profundiza el aspecto del mito de 'las dos Españas'.
} 


\section{Introducción}

En Campos de Castilla Antonio Machado poetiza la gran metáfora — que regía los discursos intelectuales al final del siglo XIX - de una dicotomía entre una España vieja, atrasada y moribunda y otra nueva, progresista y viva. "Una de las dos Españas/ ha de helar[le] el corazón" al Españolito. Es una fórmula que destaca una fisura insalvable que amenaza la unidad nacional imaginada; una fórmula que deberá impregnar la conciencia colectiva con un mito persistente porque el relato de crisis y trauma del que pretende dar cuenta es variable política e históricamente. Desde el trienio 1820-23 la metáfora de 'las dos Españas' marcaba los discursos y versiones de la historia nacional y ha sido reinventada y actualizada continuamente. En las luchas por la hegemonía ideológica de la época de la preguerra, durante la Guerra Civil y después en el franquismo, se radicalizó sistemáticamente su uso discursivo. (Baumeister 558)

Pese a los procesos de democratización en la política real y en la sociedad, la imagen polisémica condensa de forma estereotipada los frentes ideológicos que se endurecieron durante la Guerra Civil y sus secuelas.

Era éste un mito y una manera de interpretar la propia historia con la que se ha sufrido mucho en España, pero que también se habían acostumbrado, casi diría: con la que se habían familiarizado los españoles como con algo inalterable; algo que por lo menos servía para dar una primera orientación — fatalista por cierto- en el embrollo nacional. (Neuschäfer 151)

El relato metahistórico, "con su limpio enfrentamiento de contrarios y la consiguiente percepción de la realidad España partida en dos" (Juliá 148), se incorporó en la imaginación popular porque dispone de una extrema plasticidad. Hoy día la percepción de la Guerra Civil y del franquismo tanto como el fuerte bipartidismo político (PP vs. PSOE), que hace poco parecía romperse con la llegada de nuevos partidos políticos, sigue nutriendo la imagen, reafirmando viejas tesis. Tanto su génesis como su perpetuación son fruto del carácter mítico que no se comprende como "una utopía, construida con datos extrapolados de la realidad" (Cacho Viu 72), sino unas "fórmulas concebidas para estimular acción decidida en aquellos a quienes se dirigen" (Cacho Viu 72). Transmite las sensibilidades y necesidades o anhelos de la sociedad española en la que, de una forma u otra, se sigue sintiendo afinidad por una de 'las dos Españas'.

La expresión más radical de 'las dos Españas', que se enraíza en la memoria de la Guerra Civil y sus secuelas, se ve representada en las ficciones que tematizan la Guerra Civil y la dictadura franquista. Según la perspectiva de la narración la implementación del mito cumple diferentes papeles, muchas veces el de perfilar los frentes estereotipados con el fin de fomentar la superioridad moral de los 'vencidos'. En cuanto al cuestionamiento del mito de 'las dos Españas', la novela Soldados de Salamina (Javier Cercas, 2001) es crucial. Hans-Jörg Neuschäfer, por ejemplo, concluye que el libro propone una liberación "de aquel double bind ancestral que Antonio Machado ha resumido en los 'Proverbios y Cantares' de sus Campos de Castilla" (Neuschäfer 152). Para Neuschäfer, Cercas asume una perspectiva reconciliadora y el impacto de la novela daría cuenta de "la última etapa de una superación del trauma nacional del conflicto entre las dos Españas" (Delage 2). En la novela de Cercas el protagonista se niega a evocar a Antonio Machado - "verdadero emblema de la mitología nacional española" (Cachu 
Viu 70) — sin razonar sobre el proceso de mitificación que precede a tal 'canonización' del poeta. El debate abierto por Cercas muestra como las diferentes áreas culturales y políticas instrumentalizan los grandes relatos, que rodean el mito de 'las dos Españas', para conseguir sus fines. Pero mientras que Soldados de Salamina "propone superar el antagonismo" (Delage 2), otras ficciones ponen en tela de juicio la supuesta superación, o bien cicatrización, de la herida y del cainismo arcaico, reivindicando los estereotipos políticos y culturales (p.ej. las novelas de Almudena Grandes). En Corazón helado Grandes reactiva el emblema 'Machado', y los valores de los que es sinónimo, por medio de la referencia intertextual que hace el título de la novela a la imagen famosa de Campos de Castilla (Delage 3). En el libro "simultáneamente se agudizan y se dislocan las polaridades opuestas del tópico de "las dos Españas"'(Delage 1). A pesar de la gran variedad en la representación del mito, el juego dialéctico de proximidad y distancia, de unidad y disconformidad forma el núcleo de todas.

La representación de 'las dos Españas' en los videojuegos Sombras de Guerra y España en llamas, analizados en este artículo, parte de la misma base. En el comienzo del juego hay que tomar una decisión crucial: “¿Nacionales o Republicanos?”. Pero no solo es posible jugar con cada uno de los bandos, sino que la segunda parte del eslogan de Sombras de Guerra (que vale también para España en llamas) sostiene que "!Tú decides la historia!". Con ello se acentúa el aspecto más destacable de los dos videojuegos en cuestión: la posibilidad de que cada bando pueda ganar la guerra si el jugador tiene la suficiente habilidad y destreza. El elemento contrafáctico puede incitar al jugador a razonar con el acontecimiento histórico. Sin embargo, no diluye los frentes míticos, sino que perpetúa el mito de 'las dos Españas' como se verá en lo sucesivo. Parece que la representación de los dos bandos nace de una ingenuidad que considera naturalizada la hipótesis de contrastes entre las ideologías y narraciones monolíticas de la izquierda y de la derecha. Por consiguiente, la programación de los dos videojuegos da lugar a la perpetuación del mito de 'las dos Españas' y sus estereotipos políticos y culturales, aunque su carácter lúdico, determinado por la actividad física y cognitiva de los jugadores, da ocasión a su deconstrucción.

Conforme al estudio de Graeme Kirkpatrick Aesthetic Theory and the Videogame los conceptos estéticos de juego y de forma permiten considerar el videojuego una forma cultural que acentúa la participación activa del receptor. Según Kirkpatrick, es indispensable que se juegue un videojuego para experimentarlo y por lo consiguiente el acto de jugar es primordial. Los videojuegos oscilan entre la producción, o bien existencia, y la carencia de sentido, lo integran y desintegran continuamente:

video games [provide] an excess of form that overrides and negates meaning even as it repeatedly evokes it. Games need meanings; fictions an resemblances are integral to them, but the activity of playing games is powerfully corrosive to these fictions. (Kirkpatrick 9)

Aunque, por lo tanto, los elementos audio-visuales, narrativos y táctiles configuran la experiencia de juego e influyen en cómo el jugador percibe e interpreta el acontecimiento histórico tematizado, la posibilidad de corromper el sentido es esencial para la experiencia de juego. 


\section{2. "Nacionales o Republicanos" - perfilar los antagonismos y en- durecer la división}

Los dos videojuegos pertenecen a diferentes géneros y se distinguen claramente por el sistema de juego, el tipo de interactividad y también por la perspectiva visual que adoptan. Sombras de Guerra es un juego de estrategia en tiempo real mientras que España en llamas es un videojuego de disparos (o shooter) en primera persona - y sobre todo es un $\bmod ^{2}$ creado para el famoso shooter Call of Duty. En el shooter, que simula la visión de los ojos de un soldado, destacan los momentos de eficacia personal y de inmersión porque es similar a una narración en primera persona en la que el jugador asume la posición del 'yo'. En consecuencia, España en llamas es un recorrido subjetivo por las batallas más emblemáticas de la Guerra Civil. El juego de estrategia cuenta con más distancia a los sucesos, ya que importa que el jugador se haga una vista general para planear sus movimientos. En ese género predominan categorizaciones y estructuras esquemáticas. Sin embargo, los dos videojuegos se asemejan en la representación temática de la Guerra Civil y, en concreto, en cómo se refieren al mito de 'las dos Españas'.

Tanto el juego de estrategia como el shooter se prevalen del antagonismo entre los dos bandos y lo aplican a sus sistemas de juego que favorecen una confrontación entre dos equipos con la finalidad de que uno de los dos gane la contienda. Particularmente interesante son las condiciones de victoria: se aplica la regla 'eliminación de piezas' en la que el juego es ganado por el jugador quien diezma o elimina las unidades del oponente para asegurar la propia supremacía. Lo que queda al final de las campañas es o la victoria o la derrota del ejército seleccionado, lo que implica que un bando tiene que ganar. No es posible terminar la guerra antes de hora o llegar a un acuerdo entre los dos ejércitos, p.ej. repartiendo el país entre ellos. Tampoco hay ningún 'tercer partido' que pueda intervenir y diluir la dicotomía. A pesar de la posibilidad de producir un escenario contrafáctico en el que la República gana la guerra, el marco en el que se desarrolla la ficción es restringido por las condiciones de victoria. Como las campañas tienen lugar solamente en los días de guerra (1936-1939) evitan la confrontación con los precursores y las secuelas de la misma. Eso sugiere que al final siempre hay un vencedor 'legítimo' (según la destreza del jugador) y que el final de la guerra también pone fin a la escisión militar, política e ideológica, sin que se reflexione sobre cómo los 'vencedores' imponían su voluntad a los 'vencidos'. Mientras que la posible victoria de la República discute la salida histórica de la guerra, las 'dos Españas' aparecen dadas por hecho y las correspondientes cargas ideológicas se perfilan como realidades evidentes y naturalizadas. Al retomar el antagonismo se secunda a la recepción 'clásica' del mito que se centra en la contrariedad de 'las dos Españas' imaginadas.

En ambos juegos es posible jugar las campañas con un solo bando hasta terminar el juego o ir alternando. Jugar con un solo bando intensifica la identificación con este, la alternación "escenifica la frontalidad ideológica de la oposición irreductible entre las

2 "Un mod es una extensión del software que modifica un videojuego original proporcionando nuevas posibilidades, ambientaciones, personajes, diálogos, objetos, etc. En la actualidad, prácticamente todos los videojuegos importantes para PC incorporan herramientas y manuales para que exista la posibilidad de modificarlo al gusto del jugador." (Wikipedia: "Mod [videojuegos]", consultado 30 diciembre 2020). 
dos Españas" (Delage 3). La posibilidad de elegir entre los bandos y, por ende, jugar las campañas desde la perspectiva de cada uno - pero bajo las mismas condicionesequipara las perspectivas en el sentido de que básicamente ningún ejército es moralmente mejor que el otro. Por lo contrario, la configuración de los dos videojuegos afirma la legitimidad de cada perspectiva ya que el papel del enemigo, que tendrá que ser aniquilado, depende de la selección inicial del jugador o cambia constantemente si se juega alternando las campañas de los 'Nacionales' y de los 'Republicanos'.

Sombras de Guerra y España en llamas consiguen tanto la identificación como el afrontamiento ideológico entre los dos bandos por medio de símbolos y de discursos heroicos en los que el pathos es manifiesto. Asociados a la emoción y apelando a la simpatía del jugador, los monólogos, diálogos y exclamaciones patéticas - como por ejemplo "AAdelante, camaradas!” o “Hasta la victoria!”- agudizan el dualismo 'amigo/enemigo'. Según su predisposición, sus valores y creencias, el jugador se identifica con un bando u otro o experimenta una forma de identificación sustituible que cambia cada vez que cambia el equipo seleccionado.

Además de fomentar la identificación con el equipo seleccionado, los símbolos y discursos patéticos reafirman la naturalización y la contundencia de los rasgos ideológicos porque presentan la Guerra Civil como "última guerra romántica” —otro mito perpetuo- en la que los dos bandos lucharon por sus ideales. A eso corresponde que los avatares son héroes provistos de un repertorio de funciones más elaboradas y con rasgos individuales en la interfaz. Manejando el avatar, el jugador ensaya el poder de la toma de decisiones. A causa de la perspectiva visual de España en llamas, en la que el jugador y el avatar se encarnan, la experiencia de eficacia personal se profundiza. Aunque de manera diferente los dos videojuegos dan la impresión de que la Historia está hecha por héroes y que las decisiones individuales deciden sobre el destino de la humanidad. El jugador se transforma en hacedor y, literalmente, con la ayuda del teclado o del joystick, "el destino de España está en [s]us manos" (como lo sostiene el manual de Sombras de Guerra).

La narración que acompaña las campañas y los movimientos militares ejecutados por el jugador pivota alrededor de una intriga sentimental entre los protagonistas (avatares principales) de los dos bandos. Marion Barrena y Manuel, alias Ghanin Shabah, estuvieron en pareja secreta en el pasado y cuando se enteró el padre de Marion de esa relación, mandó a Manuel con el ejército africano, dónde, por la tortura que sufrió, se transformó en Ghanin Shabah y comenzó a luchar ferozmente en el lado de los ' $\mathrm{Na}$ cionales'. La confrontación de los antiguos amantes que, desde entonces, luchan por las causas antagónicas, profundiza la escisión vigente, insertando una dimensión emocional. En ninguno de los videojuegos hay un final feliz para la pareja, lo que expresa simbólicamente la oposición irreductible entre 'las dos Españas' utilizando la imagen de un amor que se transforma en odio. Parece que los dos videojuegos se aprovechan del dolor y del odio transmitido por generaciones. De ahí que el dualismo de amor y odio es una parte integral del mito de 'las dos Españas' en el que prevalecen las estructuras emotivas sacando la memoria de la Guerra Civil de su contexto histórico específico. 


\subsection{Sombras de Guerra: De cómo una 'ambientación muy cui- dada' no impide la retoma de mitos y viejas tesis}

Ya en la portada de la funda del CD-ROM los dos bandos son representados de forma simbólica por la correspondiente bandera. Cada una se encuentra en un lado de las letras del título. Sin embargo, el diseño hace suponer que se trata de una sola tela de la que son tejidas las dos banderas. En el centro del título se ve la silueta del miliciano de la muy famosa fotografía "Muerte de un miliciano" de Robert Capa, cuya autenticidad ha sido puesta en tela de juicio por distintos expertos. En la parte superior cuatro personajes de la Historia, de ambos lados (Millán Astray, Franco, Gónzalez "el campesino" y Rojo Lluch), miran al jugador de manera desafiante. Es llamativo que los de la derecha política se encuentren encima de la bandera republicana y los de la izquierda política encima de la bandera 'nacional' (reinstaurada por los rebeldes). El diseño de la portada expresa claramente la dialéctica de unidad y disconformidad y, por ende, evoca simbólicamente la fraternidad oblicua que desemboca en el supuesto cainismo de la Guerra Civil del que se sirve el videojuego. Sombras de Guerra se vale del antagonismo entre izquierda y derecha y de sus relatos monolíticos para establecer la situación inicial de la que parten las reglas y condiciones del juego. Se presentan los ejércitos adversos de acuerdo con el objetivo clásico del RTS que consiste en eliminar al enemigo para asegurar su supremacía.

La pantalla de inicio que contiene el menú de opciones representa los ejércitos seleccionables mediante símbolos. No utiliza los escudos oficiales del franquismo ni de la República, sino que inventa dos escudos con elementos que se atribuyen a los partidos en cuestión: el águila y una cruz en el lado de los 'Nacionales', una estrella, una espada y una escopeta entrecruzados en el lado de los 'Republicanos'. En general, "el título está casi ausente de simbología de uno y otro bando, lo que demuestra que en ningún caso se ha pretendido crear polémica" (Gómez). No obstante, se distingue claramente un bando del otro mediante los contextos del juego. Por ejemplo, los frentes estereotipados figuran y se condensan de forma simplista bajo los nombres de cada ejército seleccionable y sus escudos. Los nombres ya indican el 'archivo discursivo' que se ha construido alrededor de los dos bandos ideológicos. La denominación parece un envase que reduce las variedades ideológicas de cada frente a un mero compendio. Durante las campañas Sombras de Guerra recurre al imaginario popular para forjar los equipos adversarios y perfilarlos con el fin de que sean identificables y, por ende, objeto de la aniquilación enemiga.

El juego de estrategia se vale de los elementos clásicos del género. Por medio de material documental intenta autentificar el escenario. Muestra uniformes, vehículos (tanques y otros carros de combate) y personajes (soldados en sus diferentes grados) con mucha atención por los detalles en "una ambientación muy cuidada" (Manual de Sombras de Guerra). Además, la selección obligatoria al principio de una campaña diferencia claramente entre los adversarios y prefigura la perspectiva y la correspondiente identificación con el ejército seleccionado. Con respecto a las funciones de las unidades y ejércitos seleccionables, un jugador comenta en YouTube: "los ejércitos seleccionables (republicanos o nacionales) no llegan a diferenciarse mucho entre sí, y aunque esto no es un error muy importante, sí hace poco interesante jugar con uno u otro bando." En contra de la afirmación que no es "muy importante" que los dos bandos no se diferencien mucho con respecto a la jugabilidad, la equidistancia — técnicamente forzada- 
genera una equidistancia en el nivel de la ficción de la memoria sobre la Guerra Civil y por consiguiente con respecto a los aspectos sociohistóricos, políticos y éticos. En eso, Sombras de Guerra, aunque cuestione por su medialidad particular los modos de tratar la memoria sobre la Guerra Civil en los discursos literarios y artísticos, no se desvía ni de la tesis de la culpa colectiva ni de una representación clásica de 'las dos Españas'. Eugen Pfister hace hincapié en que los videojuegos con trasfondo histórico, en general, fingen autenticidad imitando con diligencia uniformes, vehículos o sonidos de escaramuza. Pero que, según la sensibilidad del tema, no simulan los auténticos trasfondos y consecuencias políticas y morales (Pfister 556). Este es el hecho en Sombras de Guerra: la pantalla de inicio, en la que el jugador debe elegir su bando, pone los dos frentes al mismo nivel. Aunque el material fílmico, que precede a la primera misión, hable de una 'sublevación' y de 'rebeldes', no se comenta la situación inicial asimétrica entre los dos bandos que tanto se refiere al armamento y las facultades militares como al hecho de que se trata de una insurrección contra un gobierno que fue instaurado por vías democráticas. Más bien, la introducción parece subrayar que la Segunda República estaba ya condenada al fracaso por culpa de un 'paternalismo genuino y tradicionalmente español' —un mito que la derecha retomará en su proyecto de nación. Al citar ese mito se perpetúan los discursos muy discutibles sobre el fracaso inevitable de la República, su supuesta ilegitimidad y la necesidad de restaurar el orden público.

Jugar videojuegos rara vez es una actividad solitaria. En nuestra era digital los videojuegos se sitúan en contextos comunicativos muy complejos, generan un universo virtual "that invokes a specific reading dynamic, [...] the process of consuming [...] is playful and cumulative" (Kirkpatrick 164). La mayoría de los juegos tiene una página web oficial y numerosas páginas web extraoficiales en las que se extiende su entorno interactivo en chats y foros, por wikis y por una variedad de producciones artísticas de aficionados. Jugar videojuegos es una actividad intensa que se realiza con amigos y forasteros en un constante intercambio de ideas y prácticas. En esos contextos se vislumbran las actitudes de los jugadores frente al mito de 'las dos Españas' y a una supuesta afinidad por una de las dos.

Las reglas de Sombras de Guerra prevén que el jugador se vale de todos los medios a su alcance para que el ejército seleccionado gane la guerra. Sin embargo, existen formas de resistencia: Hay jugadores que se oponen a esa pauta que pide la identificación con el bando seleccionado. En el "forocomunista.com" se lee por ejemplo:

igitaiaetamailua: A veces me elegia el bando nacional y jugaba mal para verles ser masacrados jajaja... pequeños placeres de la vida.

La idea de jugar con el otro bando para que este no solo pierda, sino que sea 'masacrado' muestra, por un lado, las posibilidades que ofrece el videojuego con respecto a la interacción (también en la producción de las ficciones de la memoria sobre la Guerra Civil) y revela, por el otro lado, cómo se han internalizado las concepciones estereotípicas de los dos bandos y de qué manera se ven reintegradas en los discursos actuales. 


\subsection{España en llamas: En contra de una equiparación moral}

El juego de disparos en primera persona España en llamas sigue las mismas pautas con respecto a la representación de 'las dos Españas'. Una razón significante es que la trama del videojuego se basa en la trama de Sombras de Guerra, utilizando los mismos personajes y el material fílmico de este. Como en el juego de estrategia no hay remedio: una parte tiene que ganar. La dicotomía entre el bando 'republicano' y el bando 'nacional' tampoco se diluye. Sin embargo, el juego toma posición en cuanto a una superioridad moral de los republicanos.

En la última misión, jugada desde la perspectiva del ejército nacional, los dos antiguos amantes se enfrentan y Ghanin Shabah fusila a Marion Barrena decidiendo que "sólo uno de nosotros morirá hoy, y no seré yo...". Esa decisión agudiza de forma verbal la fisura entre 'las dos Españas' que se excluyen mutuamente. La muerte de Marion Barrena simboliza la aniquilación del bando republicano, el fin trágico de un amor-odio. Por consiguiente, expresa la esencia del mito de 'las dos Españas'.

Al contrario de la perspectiva nacional, la misma misión jugada con el ejército republicano termina con la detención de Francisco Franco. Como la anterior, esta secuencia también es animada y el jugador no puede intervenir. Marion anuncia que Franco será entregado a la justicia y condenado por sus crímenes de guerra. En la misión republicana la justicia triunfa sobre la violencia o el linchamiento. Gana la idea de una posible integración del bando nacional en la España nueva y republicana. Llama mucho la atención que no es posible matar al emblema de la escisión española, Francisco Franco, lo que por un lado puede ser interpretado como una forma moral superior de los republicanos. Por el otro, puede que los creadores del juego no querían crear más polémica de la necesaria, lo que quiere decir que el hecho de que se trata de un videojuego que tematiza la Guerra Civil ya es problemático. Desde hace años la Guerra Civil española es tema de juegos de mesa estratégicos. Títulos como La Guerra Civil española del año 1981 siguen vendiéndose hasta hoy en día (la última versión es del 2009) sin crear ninguna polémica (Díez). Eugen Pfister encuentra una posible respuesta a la pregunta de por qué los videojuegos con trasfondo bélico engendran controversias. Sufren el prejuicio de no ser un medio de valor cultural y artístico. Hubo el mismo debate cuando las películas como Schindler's List se hicieron populares y temas sensibles y delicados (en este caso el Holocausto) comenzaron a circular en los contextos de la comunicación de masas. Hoy día esa clase de películas ya es considerada un medio tradicional para hacer memoria. Los videojuegos, sin embargo, llaman todavía la atención.

Mientras que en las campañas no es posible matar a Franco, la versión multijugador lo hace posible porque en ella Franco es un avatar que los jugadores pueden elegir para luchar. Un video de YouTube que lleva por título "Ostia he matado a Franco!" muestra como el avatar de un jugador se muere en el combate y los jugadores 'se mueren de risa' por haber "matado a Franco". Tanto como Javier Cercas, que en su novela Soldados de Salamina cuestiona el papel emblemático de Antonio Machado — aunque de forma pacifista_ - la versión multijugador de España en llamas permite destronar el emblema que reúne de forma ambigua a los 'vencidos' y los 'vencedores' de la Guerra Civil. La muerte de Franco en la realidad en 1975, que selló el final de la dictadura, dio tanto ocasión a la alegría como al luto. 


\section{3. ¿Game over mito de 'las dos Españas'?}

La obligación a la victoria de un bando perpetúa la (ficticia) escisión de 'las dos Españas' y muestra el binarismo ideológico que sigue estructurando los discursos sobre la memoria histórica. Los dos videojuegos se niegan a un gesto reconciliador porque no cabe dentro de la lógica de un juego de guerra clásico con el objetivo de 'neutralizar' al enemigo. Lo que sí puede motivar al jugador a interesarse por la memoria de los dos bandos es la posibilidad de alternar las campañas. El cambio de perspectiva invita al jugador a razonar con la representación estereotípica del antagonismo. Es posible empatizar con los dos ejércitos y luchar por cada una de las causas antagónicas, lo que muestra claramente que las historias y sobre todo las memorias de 'las dos Españas' están entrelazados. Sin embargo, la confrontación es necesaria para que el juego funcione. Por consiguiente, los dos videojuegos no se despiden del mito de 'las dos Españas', sino que lo retoman como parte integral. Son los jugadores y sus intervenciones corrumpentes las que reescriben el gran relato de crisis y trauma e impiden la reafirmación de viejas tesis negándose a cumplir las reglas y condiciones del juego.

\section{Videojuegos}

Mod 1936, España en llamas. 2007 (basada en: Call of Duty 2. USA, Infinity Ward 2005). Sitio web: http://spainatwar.weebly.com/descargas.html.

Sombras de Guerra. España, Legend Studios, 2007.

\section{Bibliografía}

Baumeister, Martin. “Atraso de España - Las dos Españas”. Handbuch Spanisch. Sprache, Literatur, Kultur, Geschichte in Spanien und Hispanoamerika. Für Studium, Lehre, Praxis. Ed. Joachim Born. Berlin: Erich Schmidt, 2011. 556-561.

Bender, Steffen. Virtuelles Erinnern. Bielefeld: Transcript, 2012.

Cacho Viu, Vicente. "La imagen de las dos Españas". Revista de occidente 60 (1986): 49_ 77.

Delage, Agnès. “El estereotipo político de 'las dos Españas' en El corazón helado de Almudena Grandes". La redefinición de la identidad hispánica en la literatura y el cine postnacionales. Ed. Nadia Lie, Silvana Mandolessi y Dagmar Vandenbosch. Berlín: Peter Lang, 2012. 329-343.

Díez, Julián. “'Sombras de guerra' reabre viejas heridas sobre la contienda civil”. El Pais, 3 diciembre 2007. Web. 30 diciembre 2020.

Gómez, Julio. "Análisis de Sombras de Guerra: La Guerra Civil Española (PC)". Vandal, 24 diciembre 2007. Web. 30 diciembre 2020. 
Igitaiaetamailua. "Que opinas acerca del videojuego Sombras de guerra: la Guerra Civil Española (¿Falta de respeto?)". Forocomunista. 31 octubre 2011. Web. 30 diciembre 2020.

JuanPawolker Classic. “Ostia he matado a Franco”. YouTube.com. 12 agosto 2012. Web. 30 diciembre 2020.

Juliá, Santos. Historias de las dos Españas. Madrid: Taurus, 2004.

Kirkpatrick, Graeme. Aesthetic theory and the video game. Manchester: Manchester University Press, 2017.

Kuschel, Daniela. Spanischer Bürgerkrieg goes Pop. Bielefeld: transcript, 2019.

Neuschäfer, Hans-Jörg: "La memoria del pasado como problema epistemológico: Adiós al mito de las 'dos Españas". Lugares de memoria de la Guerra Civily el franquismo: representaciones literarias y visuales. Ed. Ulrich Winter. Madrid/Frankfurt a.M.: Iberoamericana/Vervuert, 2006. 145-153.

Pfister, Eugen. Das Unspielbare spielen - Imaginationen des Holocaust in Digitalen Spielen. zeitgeschichte 43.4 (2016): 250-263. 